\title{
Willingness to Pay for Hormone Replacement Therapy ${ }^{*}$
}

\author{
Niklas Zethraeus and Per-Olov Johansson \\ Department of Economics, Stockholm School of Economics, Stockholm, Sweden
}

Working Paper Series in Economics and Finance No. 214

December 1997

(Address for Correspondence: Niklas Zethraeus, Stockholm School of Economics, Box 6501, S - 11383

Stockholm, Sweden. Phone: +46 8736 9640; Fax: +46 83022 26; E-mail: henz@hhs.se)

\begin{abstract}
This study addresses the question of willingness to pay (WTP) for hormone replacement therapy (HRT) in order to alleviate menopausal symptoms. A utility model is specified where the individual obtains utility from consumption of goods and health. The purchase of a treatment is represented as a shift in the health production function during the treatment period. The mean WTP for the HRT is estimated using a parametric and a nonparametric method. The mean WTP based on these two methods is similar in both cases and amounts to about SEK 40,000 per year. Further, it is shown that the mean WTP is above the mean treatment costs of HRT. Finally, the implied WTP per gained quality adjusted life year is estimated at about SEK 120,000 and SEK 160,000 based on the rating scale (RS) and time tradeoff (TTO) methods, respectively.
\end{abstract}

Keywords: Hormone Replacement Therapy, Menopausal Symptoms, Willingness to Pay.

JEL Classification: D61, D91, I10, I12.

Acknowledgements: Comments from Magnus Johannesson and participants at the Health Economic Seminars at the Stockholm School of Economics are highly appreciated. The National Corporation of Swedish Pharmacies financially supported the study. 


\section{$\underline{\text { 1. Introduction }}$}

At menopause, around the age of 50, about 80 percent of women experience menopausal symptoms (Daly et al. 1993). Symptoms, for example, are hot flushes, night sweats and atrophy-related symptoms in the urogenital tract. The presence of menopausal symptoms decreases the quality of life of women. The loss in quality of life may be substantial, which is indicated in Daly et al. (1993). Hormone Replacement Therapy (HRT) may alleviate these symptoms and thus increase the quality of life for symptomatic women (Karlberg et al. 1995; Wiklund et al. 1993). HRT may also have a cardioprotective effect and offers protection for osteoporosis and related fractures (Wiklund et al. 1993). The evidence on the effect of HRT on breast cancer is inconclusive (Stanford et al. 1995; Colditz et al. 1995).

In recent years several studies have focused on the benefits and costs of HRT (Weinstein 1980; Weinstein and Schiff 1983; Weinstein and Tosteson 1990; Tosteson et al. 1990; Tosteson and Weinstein 1991; Cheung and Wren 1992; Daly et al. 1992; Tosteson et al. 1993). These are all examples of cost-utility analyses where costs are measured in monetary units and benefits are measured in gained quality adjusted life years. An alternative way to assess the value of the change in quality of life due to HRT is to measure the willingness to pay (WTP) for HRT. Then it is possible to compare, directly, the benefits of HRT, measured in monetary units, with the costs of HRT. Further, it also becomes possible to calculate the WTP for a gained QALY, which may be compared to the costs for producing a gained QALY.

The purpose of the study is to use the contingent valuation method (CVM) to analyse how much symptomatic women are willing to pay for HRT. It is assumed that the woman maximises her

*A revised version of this paper is accepted for publication in Health Economics. 
expected present value utility and that she consumes goods and values her health, which is produced through a health production function. HRT is modelled as a (parametric) shift in the health production function. A WTP measure for the shift in the health production function is then defined. The model is described in Section 2. Section 3 presents the methods, while the results are found in Section 4. Section 5 concludes the paper.

\section{The model}

In this section we develop a model of an individual who maximises her expected present value utility. She consumes goods and values her health, which is produced through a health production function. The treatment under investigation, i.e. HRT, is modelled as a shift in the health production function. Since the survival probability is assumed to be a positive function of an individual's health capital, the considered treatment will, in addition to its direct impact on health and utility, also affect her survival probability. A WTP measure for the shift in the health production function is also defined.

Let us consider an individual aged $T$ years whose time $s$ instantaneous utility function is denoted $u(s)=u[c(s), h(s) ; T ; s]$ for $s \geq T$. Instantaneous utility at time $s$ depends on the levels of consumption of goods $c(s)$ and the stock of health capital $h(s)$. The instantaneous utility $u($.$) at$ time $s$ may also depend on the individual's age at that time, as is indicated by $T$ and $s$ in the instantaneous utility function. Integrating this function between zero and $t$ yields the total utility of living for $t$ years. 
The present value utility at her current age $T$ attained from surviving with certainty another $t-T$ 'years' is written as follows:

$U(t ; T)=\int_{T}^{t} u[c(s), h(s) ; T ; s] \alpha(s ; T) d s$

where $u[c(s), h(s) ; T ; s]$ is a twice continuously differentiable instantaneous utility function on $(0, \infty), \partial u[.] / \partial b(s)=u_{b}[c(s), h(s) ; T ; s]>0$ for $b(s)=c(s), h(s), \partial^{2} u[.] / \partial b(s)^{2}=u_{b b}[c(s), h(s) ; T ; s]<$ $O$ for $b \in[0, \infty)$, and $\alpha(s ; T)$ is a strictly positive and continuously differentiable discount factor on $[0, \infty)$, in equation (1) discounting back utility to time $T$. Unless otherwise stated, we assume that present value utility $U($.$) is increasing in t$, and that $U($.$) may be 'age-dependent' also through$ a time-dependent marginal time preference $-[d \alpha(s ; T) / d s] / \alpha(s ; T)=\theta(s)$. Next, we introduce the survivor function $\mu(t)$ of the individual:

$\mu(t)=1-F(t)=e^{-\int_{0}^{t} \delta[h(s), s] d s}=e^{-\Delta(t)}$

where $\mu(0)=1$ and $\lim _{t \rightarrow \infty} \mu(t)=0$, i.e. $\mu(t)$, which for simplicity is assumed to be exponential, yields the probability that the individual survives for at least $t$ periods/years, $F(t)$ is the cumulative distribution function yielding the probability that the individual survives at most until time ('age') $t$, and the distribution of $t$ is given by the hazard function $\delta[h(t), t] d t$, i.e. the probability that the individual dies in the short interval $(t, t+d t)$ conditional on having survived to time ('age') $t$. Thus the hazard $\delta[h(t), t]$ is a function of both the stock of health capital at time $t$, and the age of the individual. We assume that the intensity parameter $\delta[$.$] is non-negative,$ bounded away from zero, and decreasing in $h($.$) and increasing in t$. This means that we assume 
that health capital not only increases the quality of life through its presence in the utility function, but also has an impact on the expected life-length of the individual. Let us assume that the individual has survived until time (age) $T$. Then, her remaining expected present value utility, conditional on having survived to time $T$, can be written as follows:

$$
E\left(u_{T}\right)=\int_{T}^{\infty} \frac{U(t) F_{t}(t)}{\mu(T)} d t=\int_{T}^{\infty} u[c(t), h(t) ; T ; t] \alpha(t ; T) \mu(t ; T) d t
$$

where $\mu(t ; T)=\mu(t) / \mu(T)$ is the probability of surviving at least until time $t$ conditional on having survived until time $T$. The final equality in equation (3) is obtained by integration by parts; note that $F_{t}(t)=-\mu_{t}(t)$ in equation (3) and a subscript $t$ denotes a partial derivative with respect to $t$, i.e. $F_{t}(t)$ is the density function for $t$. The middle expression in equation (3) yields the present value utility at time $T$, conditional on having survived that long, of living for exactly $t$ periods multiplied by the probability of living that long, i.e. $F_{t}(t)$, summed (integrated) from $t=T$ to $t=$ $\infty$. The right-hand side expression in equation (3) yields the present value at time $T$ of instantaneous utility at time $t$ multiplied by the probability of surviving for at least $t-T$ periods beyond $T$ summed (integrated) over the entire time horizon.

The budget constraint faced by the individual considered is written as follows:

$\dot{k}(t)=r k(t)+y(t)-c(t)-x(t) \quad ; k(T)=k_{0}$

where a dot denotes a time derivative, $k(t)$ is wealth at time $t, r$ is the, for simplicity, constant rate of interest, $y(t)$ is a fixed income at time $t, c(t)$ is consumption at time $t, x(t)$ denotes 
resources set aside for health investments and $k_{0}$ is a constant. The accumulation of health follows the equation:

$\dot{h}(t)=f[x(t), t ; \beta(t)]-\gamma h(t) \quad ; h(T)=h_{0}$

where $\beta(t)$ is a shift parameter, $\gamma$ is a depreciation factor, $f[$.$] is a strictly concave health$ production function in $x(t), f \in \mathrm{C}^{2}$, which is increasing in $x(t)$ and decreasing in time, and $h_{0}$ is a constant. Thus, the individual's age has a direct impact on her ability to produce health capital.

The assumed objective of the individual is to maximise her expected present value utility in equation (3) subject to the dynamic budget constraint in equation (4), the health accumulation equation (5) and the differential equation for $\Delta(t)$ :

$\dot{\Delta}(t)=\delta[h(t), t] \quad \Delta(0)=0$

There are also transversality conditions associated with the individual's maximisation problem, see Appendix 1. The expected present value Hamiltonian corresponding to this maximisation problem is:

$$
\begin{gathered}
H(t)=u[c(t), h(t) ; T ; t] \alpha(t ; T) \mu(t ; T)+\lambda^{k}(t ; T)[r k(t)+y(t)-c(t)-x(t)] \\
+\lambda^{h}(t ; T)[f[x(t), t ; \beta(t)]-\gamma h(t)]+\lambda^{\mu}(t ; T) \delta[h(t), t]
\end{gathered}
$$


where $\lambda^{i}(t ; T)=\lambda^{i}(t)[\alpha(T) \mu(T)]^{-1}$ for $i=k, h, \mu$ is an expected present value costate variable (at time $T$, conditional on having survived until time $T$ ). Necessary conditions for an optimal solution to the individual's decision problem are stated in the Appendix 1.

Let us assume that the individual has solved the above maximisation problem. Then, we can define her expected remaining present value utility at time $T$, conditional on having survived until time $T$, as follows ${ }^{1}$ :

$$
V(T)=\int_{T}^{\infty} u\left[c^{*}(t), h^{*}(t) ; T ; t\right] \alpha(t ; T) \mu(t ; T) d t
$$

where $V(T)$ denotes the value function, i.e. the solution of the maximisation problem in equations (3)-(6), conditional on having survived until age $T$ and an asterisk refers to an optimal value. We model HRT as a parametric shift in the health production function ${ }^{2}$. Let us assume that $\beta(t)$ is a shift variable whose initial value is equal to zero for all $t$. We model the treatment as a marginal shift $d \beta(t)$ in the health production function in the time interval $[T, T+\varepsilon)$, where $\varepsilon$ is an arbitrary positive number. The treatment improves the individual's ability to 'produce' health over that time interval. Note that an improved health will also affect the individual's survival probability since $\partial \mu(T) / \partial h(T)>0$.

According to the dynamic envelope theorem, the total impact on the value function of a small parametric shift is found by taking the partial derivative of the present value Hamiltonian with

\footnotetext{
${ }^{1}$ We here ignore the possibility that the optimal plan is time inconsistent (due to the properties of $u(),. \alpha($.$) and/or$ $\mu()$.$) ; see, for example, Blanchard and Fischer (1989) for details.$

${ }^{2}$ Alternatively, we could have modelled the treatment as causing a shift in the health depreciation rate $\gamma$, i.e. the treatment slows the deterioration of the individual's health. However, this approach would produce results which are similar to those reported below.
} 
respect to the parameter and integrating along the optimal path over the planning horizon ${ }^{3}$ (or the interval $T$ to $T+\varepsilon$ ). Thus, we differentiate the value function with respect to $\beta(t)$ (evaluated at $\beta(t)$ =0) to obtain:

$$
\begin{gathered}
d V(T)=(\partial V(T) / \partial \beta) d \beta=\int_{T}^{\infty}\left[d H^{*}(t) / d \beta(t)\right] d \beta(t)=\int_{T}^{T+\varepsilon}\left[\partial H^{*}(t) / \partial \beta(t)\right] d \beta(t)= \\
=[\alpha(T) \mu(T)]^{-1} \int_{T}^{T+\varepsilon} \lambda^{h^{*}}(t) f_{\beta}[x(t), t ; \beta(t)]
\end{gathered}
$$

where a subscript $\beta$ refers to a partial derivative with respect to $\beta(t), \lambda^{h^{*}}(t)$, which can be interpreted as a present value shadow price on health, discounts time $t$ values to time 0 and $[\alpha(T)]^{-1}$ shifts present values from time zero to time $T$. The integral in equation (9) yields the change in expected present value utility (at time 0 ) due to a parametric change in the health production function over the time interval $T$ to $T+\varepsilon$. This value is discounted to time $T$, through $[\alpha(T)]^{-1}$, and adjusted, through $[\mu(T)]^{-1}$, for the fact that the individual has survived until time $T$.

The individual pays an amount $d I(T)$ at time $T$ in exchange for the considered change in the parameter $\beta$. We model this by defining fixed income at time $T$ as $y(T)=Y(T)+I(T ; \beta)$, where $Y($.$) is a fixed income, I()=$.0 for $\beta=0$, and $d I(T)=[\partial I(.) / \partial \beta] d \beta$. The 'price' $d I(T)$ is such as to keep the individual at her initial level of expected present value utility following a change in the individual's survivor function. Proceeding in the same way as in equation (9), one arrives at the following expression:

${ }^{3}$ The reader is referred to Caputo (1990), Johansson and Löfgren (1994), LaFrance and Barney (1991) and Seierstad and Sydsaeter (1987) for details on how to use the value function in comparative dynamics. 


$$
(\partial V(T) / \partial \beta) d \beta=[\alpha(T) \mu(T)]^{-1}\left[\int_{T}^{T+\varepsilon} \lambda^{h^{*}}(t) f_{\beta}[.] d \beta(t)-\lambda^{k^{*}}(T) d I(T)\right]=0
$$

where $\lambda^{k^{*}}(T)[\alpha(T) \mu(T)]^{-1}$ can be interpreted as the current value marginal utility of income (wealth) at time $T$ conditional on having survived that long. Dividing through equation (10) by $\lambda^{k^{*}}(T)$ converts the expression from units of utility to monetary units. Thus by estimating $d I(T)$, we get an estimate of the conditional WTP for a small change in the health production function over the time interval $T$ to $T+\varepsilon$. If a woman is offered the treatment, i.e. HRT, for a price SEK $P$ she will accept the offer if $P \leq d I$ while she will refuse the offer if $P>d I$.

There may also be intrahousehold altruism in the sense that her spouse cares for her health and welfare, i.e. his utility function contains her health as an argument. If so, we would arrive at an expression similar to equation (10) for the husband, but with the integrand replaced by $\left[\partial u^{M}(.) / \partial h(t)\right] d h(t)$, where $u^{M}($.$) is the utility function of the husband. In this case, the$ household's total WTP exceeds $d I$ in equation (10). Possibly, also elder children are willing to contribute financially to the treatment.

\section{Methods}

A questionnaire was consecutively administered to 104 women recruited from the Department of Gynaecology at Södertälje Hospital during the period February 6, 1995 to March 18, 1996. In Sweden, at the time of the study, a woman had to pay SEK 160 for the most costly pharmaceutical product in a prescription and SEK 60 per each further product in the prescription. The patient charge per surgery visit amounted to about SEK 120. However, the largest amount to pay for pharmaceutical products and outpatient care each year was SEK 
1,800. The National Social Insurance Board (NSIB) paid for the overshooting cost for pharmaceuticals and outpatient care. The mean age of the entire patient group was 52.2 years (range 45-65 years). 82 percent of the women were treated with oestrogen in combination with a progestin, while 18 percent were treated with oestrogen alone. Women treated with oestrogen alone were all hysterectomised. A total of 51 percent of the women were given a transdermal HRT preparation while 49 percent were given pills. The mean treatment duration for the women was 3 years. After their consultation with the clinic doctor, a nurse at the clinic interviewed all women. The criteria for eligibility were that the women were between 45 and 65 years of age and that they had been treated with HRT for at least a period of 1 month.

The interview consisted of three parts. In the first part the woman was asked to indicate her health status before initiating HRT and her present health status with HRT on a rating scale (RS) between 0 (dead) and 100 (full health). The RS method is a method that is commonly used to estimate the quality of life weights to construct quality-adjusted life-years (QALYs). To get the QALY weight with the RS method the score on the scale is divided by 100 (for a RS between 0 and 100), e.g. if a woman place her current health state on 70 the QALY weight will be 0.7 (70/100). Based on the answers to the two RS questions we estimated the QALY weight with and without HRT.

Another method used to estimate QALY weights is the time trade-off (TTO) method (Drummond et al. 1987). The TTO method involves a trade-off between quantity and quality of life. An individual is asked to state the number of years in full health followed by death that is deemed as being equivalent to a specific number of years in the health state to be assessed, followed by death. The number of years in full health is then divided by the number of years in the health state to be assessed to obtain the QALY weight. If for instance a woman thinks 
that 20 years in full health followed by death is of equal value to 30 years with menopausal symptoms followed by death, the QALY weight for mild menopausal symptoms is 0.67 (20/30). In the study the woman was asked two TTO questions to estimate the QALY weight with and without HRT. The first TTO question was phrased as: "Suppose that you would experience the symptoms you had before the HRT was initiated for a period of 30 years. Indicate on the scale below how many years in full health followed by death you consider to be equivalent to 30 years with the experienced symptoms followed by death." This question was then repeated for the current health status of the woman with HRT.

In the third part of the interview the WTP for HRT was investigated using the CVM. In the CVM, survey methods are used to investigate the hypothetical WTP for a good. The CVM was originally developed in the environmental field to measure the value of changes in the environment, but recently a number of health care applications have also appeared (Johannesson 1996; Johansson 1995). In Sweden the CVM has been used in several applications, e.g. to investigate the WTP for antihypertensive therapy (Johannesson and Johansson 1996; Kartman et al. 1996; Johannesson et al. 1991; Johannesson et al. 1993).

Contingent valuation questions can be classified either as open-ended or binary contingent valuation questions (Mitchell and Carson 1989). In open-ended questions the maximum willingness to pay is elicited from each respondent, and in binary questions each respondent only accepts or rejects one price (bid). By varying the price in different subsamples the mean and median WTP can be estimated based on binary questions (Hanemann 1978, 1984). Due to problems of non-response a bidding game is often used to elicit the WTP in open-ended questions (Randall et al. 1974). A bidding game resembles an auction. A first bid is made to the respondent, who accepts or rejects, and then the bid is raised or lowered depending on the 
answer. The process goes on until the respondent's maximum WTP is reached. An important problem when using a bidding game is that the WTP is often affected by the first bid made (Kartman et al. 1996; Rowe et al. 1980; Boyle et al. 1985; Stålhammar 1996). This is referred to as starting point bias in the literature (Kartman et al. 1996; Mitchell and Carson 1989; Rowe et al. 1980; Boyle et al. 1985; Stålhammar 1996). Due to the problems of open-ended questions most studies in the environmental field now use binary contingent valuation questions. The use of binary questions was also recommended by an expert panel, appointed by the National Oceanic and Atmospheric Administration (NOAA) in the US, to assess the validity and reliability of the CVM (NOAA 1993).

The CVM based on binary questions is, however, not without problems, and important issues remain to be resolved in order to establish the validity of the method. The two perhaps most important problems are that some experimental results indicate that hypothetical WTP overestimates real WTP, and that some studies indicate that hypothetical WTP is insensitive to the size of the programme (often referred to as insensitivity of scope). To test the validity of the WTP estimates in a contingent valuation study, it can be tested whether the hypothesised theoretical relationships are supported by the data (Mitchell and Carson 1989). It may for instance, be tested whether the WTP increases with income and whether the WTP increases with the size (scope) of the programme. In the health field testing for scope would mean testing whether the WTP increases with the size of the health change.

In this study we used a binary contingent valuation question, which means that each individual is asked if they would pay a specific price $(P)$ or not. By varying the price in different subsamples it is possible to trace the relationship between the price and the proportion of individuals who are willing to pay. 
In the WTP question the woman was asked if she would continue her current HRT if she had to pay SEK $P$ per month out of her own money. The price $(P)$ was randomly varied between SEK 100 and SEK 10,000 in eight different subsamples, and each individual only received one of these prices ${ }^{4}$. The eight different prices were SEK 100, SEK 500, SEK 1,000, SEK 1,500, SEK 2,000, SEK 3,000, SEK 5,000 and SEK 10,000 (Appendix 2) ${ }^{5}$. Data was also collected about the following socio-economic variables: pre-tax household income, education level, age, and household size.

We attempted to estimate a per capita demand function for the considered (take it or leave it) commodity, i.e. we wanted to estimate the probability that the commodity would be purchased. In estimating the probability of agreeing to pay a specified amount of money $P$ in exchange for the considered treatment, i.e. HRT, we assumed a logistic model. The acceptance probability $\Pi$ is written as follows:

$$
\Pi=F(P)=1 /\left[1+e^{-\Delta v}\right]
$$

where $F(P)$ is the 'survivor' function yielding the probability of accepting to pay at least SEK $P$ in exchange for the treatment, and $\Delta v$ is the change in utility caused by the considered improvement in health if the person pays SEK $P$ for the improvement. In what follows, we assume a linear approximation of the change in utility: $\Delta v=\eta_{0}+\eta_{1} P+\eta_{2} h+\eta_{3} S$, where $h$ is a measure of the change in health status (or quality of life) due to the treatment, $S$ is a vector of

\footnotetext{
${ }^{4}$ The bid vector was established after a small pilot study of 12 patients.

${ }^{5} \mathrm{SEK}=$ Swedish crowns. The exchange rates August, 1997 were: GB£1 = SEK 12.7; US\$1 = SEK 8.0.
} 
socio-economic variables, $\eta_{i}$ for $i=0,1,2$ are parameters to be estimated, and $\eta_{3}$ is a vector of parameters to be estimated.

In order to estimate the mean WTP for HRT the following equation was estimated ${ }^{6}$ :

$$
\ln [\Pi /(1-\Pi)]=\eta_{0}+\eta_{1} P+\eta_{2} h+\eta_{3} S
$$

As can be seen from equation (11), the regression equations predict that a certain proportion of respondents have a negative WTP since $\Pi$ will approach one as $P$ approaches minus infinity. However, medical treatment is a private commodity, which you freely may or may not elect to buy. For this reason, we rule out a negative WTP in the estimation of the mean WTP for the treatment. WTP is set equal to zero for the proportion of respondents which are predicted to have a negative WTP. In the case where the WTP is non-negative, but the probability of a zero WTP is strictly positive, the mean WTP is equal to (Johansson 1995; O'Conor 1995):

$d I=\int_{0}^{\infty}\left[1 /\left(1+e^{-\left(\eta_{4}+\eta_{1} P\right)}\right)\right] d P=-\left(1 / \eta_{1}\right) \ln \left[1+e^{\eta_{4}}\right]$

where $d I$ denotes the mean WTP for the treatment and $\eta_{4}$ denotes the magnitude of the constant term in equation (11) when the elements of $S$ and $h$ are assigned particular values. The mean WTP was estimated with the explanatory variables set at their sample means. Thus, we are estimating WTP for an average respondent.

\footnotetext{
${ }^{6}$ The following equation was also estimated: $\ln [\Pi /(1-\Pi)]=\eta_{0}^{\prime}+\eta_{1}^{\prime} \ln (P)+\eta_{2}^{\prime} h+\eta_{3}^{\prime} S$. However, since
} 
To estimate the mean and median WTP for HRT based on the answers to the contingent valuation question, a non-parametric method was also used (Kriström 1990). With this method, the proportions of yes answers at the different price levels were used to construct a curve that shows the relationship between the price and the proportion of yes answers. This curve can be interpreted as a demand curve and the mean WTP is measured as the area below the curve. In the estimation of the mean WTP we assumed that the highest WTP is equal to the highest price of SEK 10,000 used in the study. We also assumed that every woman would continue her HRT if the bid was SEK 0. The median WTP is the price where 50 percent would accept to pay and 50 percent would reject to pay.

\section{$\underline{4 . ~ R e s u l t s}$}

Table 1 shows mean values and standard deviations in parenthesis for the included explanatory variables in the logistic regression equations according to (12). It can be noted that the patient group is relatively homogeneous with respect to age which reports a standard deviation of 3.87. This is explained by the inclusion criterion which restricts the patient sample to women at the age of 45 to 65 years.

\section{TABLE 1 IN HERE}

Table 2 shows the results of the logistic regressions of the intention to pay for the HRT. We report two goodness-of-fit measures: the percentage of correctly predicted responses and the likelihood ratio index (LRI) (Greene 1993). The estimated parameter of the bid variable is significant at the 1 percent level in the two regressions with the expected sign. In the first

$\left[1 / \eta_{1}^{\prime}<-1\right]$ the integral did not converge, resulting in an infinite willingness to pay for HRT. 
regression the perceived change in health status is represented by the change in the TTO score with and without HRT. The estimated parameter of $\Delta \mathrm{TTO}$ has the expected sign and is significant at the 10 percent level using a one-sided t-test ${ }^{7}$. The socio-economic variables are not significant but have the expected signs. In the second regression the perceived change in health is represented by the change in the RS score with and without HRT. The estimated parameter of $\Delta \mathrm{RS}$ has the expected sign and is significant at the 10 percent level using a one-sided t-test ${ }^{8}$. The estimated mean WTP in the two regression equations is SEK 3,772 and SEK 3,651 per month, respectively ${ }^{9}$.

\section{TABLE 2 IN HERE}

Figure 1 below shows the relationship between the price on the WTP question and the proportion of patients accepting to pay the price.

\section{FIGURE 1 IN HERE}

Based on the curve in Figure 1 the mean and median WTP were estimated. The mean and median WTP was SEK 3,518 and SEK 2,000 respectively. Thus, 50 percent of the women accept to pay SEK 2,000 for continuing their treatment of menopausal symptoms.

\footnotetext{
${ }^{7}$ This test is relevant for the hypothesis that the perceived change in health status represented by TTO or RS increases the probability of agreeing to pay. For a further discussion of one-sided hypothesis tests, see Mitchell and Carson (1989).

${ }^{8} \mathrm{~A}$ reason why the health status variables are significant only at the 10 percent level using a one-sided test, may be measurement errors in these variables (according to TTO and RS). Measurement errors in one variable implies that the estimated coefficient of the variable is biased towards zero which is denoted attenuation (Greene 1993) ${ }^{9} \mathrm{We}$ also tested for if there was a significant difference in the WTP of patients given pills versus patients given transdermal HRT preparations. No significant difference was found.
} 
Finally, the implied WTP for a gained QALY was calculated by dividing the mean WTP (Table 2) by the mean gain in quality of life (Table 1). Based on the TTO method the WTP per gained QALY was estimated at SEK 156,100. Based on the RS method the WTP per gained QALY was estimated at SEK 118,400.

\section{Concluding remarks}

The purpose of this study was to use the CVM to analyse how much symptomatic women are willing to pay for HRT. The mean WTP per month for HRT is estimated at about SEK 3,700 using logistic regression analysis. The mean WTP per month using a non-parametric method is estimated at about SEK 3,500. The results based on the parametric and non-parametric method are thus similar and the yearly mean WTP for HRT amounts to about SEK 40,000. This amount can be compared to the yearly mean WTP for reducing high blood pressure which was estimated at about SEK 9,600 (Johannesson et al. 1993). The WTP for HRT is thus quite high and can be compared with the yearly mean pre-tax household income in the sample of SEK 334,000. An average woman is then prepared to pay 12 percent of her yearly pre-tax household income for continuing the HRT. In Johannesson et al. (1993) an average individual was prepared to pay 4 percent of his/her yearly pre-tax household income for continuing the treatment for high blood pressure.

The estimated equations are in accordance with the predictions of the theory. An increased price reduces the demand for HRT and an increased perceived change in health status between HRT and no HRT implies that the WTP for HRT increases. Also the education variable was significant and showed that a higher education level implied an increased WTP for HRT. This result conforms with the predictions of the Grossman's investment model where education is positively related to health because education increases the productivity of producing health 
(Grossman 1972). Thus, the marginal cost of investing in health is reduced. A given increase in health status is more easily produced if a woman has a higher education level.

The mean WTP can also be compared with the treatment costs of HRT. Based on the total patient sample we estimated the yearly mean treatment costs of $\mathrm{HRT}^{10}$. The annual treatment costs per patient amounted to about SEK 1,600 for patients treated with oestrogen alone and to about SEK 2,300 for patients treated with oestrogen in combination with a progestin. Thus, the yearly mean WTP for HRT is well above the yearly mean treatment costs associated with HRT.

The implied WTP for a gained QALY was also calculated. Based on the TTO method the WTP per gained QALY was estimated at SEK 160,000. Based on the RS method the WTP per gained QALY was estimated at SEK $120,000^{11}$. These figures may be compared to the costs for producing QALYs. If the WTP for a gained QALY exceeds the costs for producing a gained QALY, it is indicated that the treatment is motivated from an economical perspective.

The results in this study demonstrate that the increase in quality of life from using HRT greatly exceeds the assumed increases made in earlier studies. Weinstein, for instance, assumed an increase in the quality of life weight of 0.01 due to HRT for women with menopausal symptoms (Weinstein 1980; Weinstein and Schiff 1983). This shows the importance of carrying out empirical studies on quality of life rather than making arbitrary

\footnotetext{
${ }^{10}$ The treatment costs included the costs for the drugs, the physician's visits, and the patients' time and travelling costs. Costs for estrogen only: Drugs SEK 831, 1 physician outpatient visit SEK 601, costs for time and travelling SEK 180; Costs for estrogen combined with a progestin: Drugs SEK 1,119, 1.5 physician outpatient visit SEK 901, time and travelling SEK 270.

${ }^{11}$ In Sweden the price per QALY gained is implicitly stated in cost-benefit analysis of road investments where the price per discounted QALY gained was estimated at about SEK 700,000 (The discount rate was 3\%; Johannesson et al. 1997).
} 
assumptions. Thus, the high WTP for HRT for symptomatic women can be explained by a considerable increase in the quality of life in terms of changes in the TTO and $\mathrm{RS}^{12}$.

${ }^{12}$ The improvement in the quality of life based on the RS method is similar to the results in a study by Daly et al. 1993. 


\section{REFERENCES}

Blanchard O, Fischer S. Lectures on Macroeconomics. Cambridge: MIT Press, 1989.

Boyle KJ, Bishop RC, Welsh MP. Starting point bias in contingent valuation bidding games. Land Economics 1985; 61: 188-194.

Caputo MR. How to do comparative dynamics on the back of an envelope in optimal control theory. Journal of Economic Dynamics and Control 1990; 14: 655-83.

Cheung AP, Wren BG. A cost-effectiveness analysis of hormone replacement therapy in the menopause. The Medical Journal of Australia 1992; 156: 312-16.

Colditz GA, Hankinson SE, Hunter DJ, Willett WC, Manson JE, Stampfer MJ, Hennekens C, Rosner B, Spezer FE. The use of estrogens and progestins and the risk of breast cancer in postmenopausal women. New England Journal of Medicine 1995; 332: 1589-93.

Daly E, Roche M, Barlow D, Gray A, McPherson K, Vessey M. HRT: An analysis of benefits, risks and costs. British Medical Bulletin 1992; 48: 368-400.

Daly E, Gray A, Barlow D, McPherson K, Roche M, Vessey M. Measuring the Impact of Menopausal Symptoms on Quality of Life. British Medical Journal 1993; 307: 836-840.

Drummond MF, Stoddart GL, Torrance GW. Methods for the Economic Evaluation of Health Care Programmes. Oxford: Oxford Medical Publications, 1987.

Greene WH. Econometric Analysis, Second Edition. New York: Macmillan, 1993.

Grossman M. On the Concept of Health Capital and the Demand for Health. Journal of Political Economy 1972; 80: 223-255.

Hanemann MW. Welfare evaluations in contingent valuation experiments with discrete responses. American Journal of Agricultural Economics 1984; 66: 332-341.

Hanemann MW. A methodological and empirical study of the recreation benefits from water quality improvement. Ph.D. Dissertation, Harvard, 1978.

Johannesson M, Jönsson B, Borgquist L. Willingness to pay for antihypertensive therapy: results of a Swedish pilot study. Journal of Health Economics 1991; 10: 461-474.

Johannesson M, Johansson P-O, Kriström B, Gerdtham U-G. Willingness to pay for antihypertensive therapy: further results. Journal of Health Economics 1993; 12: 95-108.

Johannesson M, Johansson P-O. To be, or not to be, that is the question: An empirical study of the WTP for an increased life expectancy at an advanced age. Journal of Risk and Uncertainty 1996; 13: 163-174.

Johannesson M. Theory and Methods of Economic Evaluation of Health Care. Dordrecht, The Netherlands: Kluwer Academic Publishers, 1996. 
Johannesson M, Meltzer D, O'Conor R. M. Incorporating future costs in medical costeffectiveness analysis: Implications for the cost-effectiveness of the treatment of hypertension. Medical Decision Making 1997; 17: 382-389.

Johansson P-O. Evaluating Health Risks. An Economic Approach. Cambridge: Cambridge University Press, 1995.

Johansson P-O, Löfgren K-G. Comparative dynamics in health economics: some useful results. Working Paper Series in Economics and Finance. 1994, 17. Stockholm: Stockholm School of Economics.

Karlberg J, Mattsson L- $\AA$, Wiklund I. A quality of life perspective on who benefits from estradiol replacement therapy. Acta Obstetricia et Gynecologica Scandinavica 1995; 74: 367372 .

Kartman B, Andersson F, Johannesson M. Willingness to pay for reductions in angina pectoris attacks. Medical Decision Making 1996; 16: 248-253.

Kriström B. A non-parametric approach to the estimation of welfare measures on discrete response valuation studies. Land Economics 1990; 66: 135-139.

LaFrance JT, Barney DL. The envelop theorem in dynamic optimization. Journal of Economic Dynamics and Control 1991; 15: 355-85.

Mitchell RC, Carson RT. Using Surveys to Value Public Goods: the Contingent Valuation Method. Washington D.C.: Resources for the Future, 1989.

National Oceanic and Atmospheric Administration. Report of the NOAA panel on contingent valuation. Federal Register. 1993; 58: 4602-4614.

O'Conor RM. Consumer-Patient Valuation of Drug Safety and Efficacy. Ph.D. Dissertation, Department of Economics, University of Kentucky, 1995.

Randall A, Ives BC, Eastman C. Bidding games for valuation of aesthetic environmental improvements. Journal of Environmental Economics and Management 1974; 1: 132-149.

Rowe RD, d'Arge RC, Brookshire DS. An experiment on the economic value of visibility. Journal of Environmental Economics and Management 1980; 7: 1-19.

Seierstad A, Sydsaeter K. Optimal Control Theory with Economic Applications. New York: North-Holland, 1987.

Stanford JL, Weiss NS, Voigt LF, Daling JR, Habel LA, Rossing MA. Combined estrogen and progestin hormone replacement therapy in relation to risk of breast cancer in middle-aged women. Journal of the American Medical Association 1995; 274: 137-42.

Statistisk Årsbok 96 [Statistical Yearbook of Sweden]. Stockholm, Sweden: Norstedts Tryckeri AB, 1995. 
Stålhammar N-O. An empirical note on willingness to pay and starting point bias. Medical Decision Making 1996; 16: 242-247.

Tosteson A., Rosenthal DI, Melton LJ, Weinstein MC. Cost-effectiveness of screening perimenopausal white women for osteoporosis: bone densitometry and hormone replacement therapy. Annals of Internal Medicine 1990; 113: 594-603.

Tosteson A, Weinstein MC. Cost-effectiveness of hormone replacement therapy after the menopause. Baillière's Clinical Obstetrics and Gynaecology 1991; 5(4): 943-59.

Tosteson A. A review and update of cost-effectiveness of hormone replacement therapy in the menopause. In Cosséry J-M, ed. Medical-Economic aspects of Hormone Replacement therapy, The Parthenon Publishing Group, 1993.

Weinstein MC. Estrogen use in postmenopausal women: costs, risks, and benefits. New England Journal of Medicine 1980; 303: 308-16.

Weinstein MC, Schiff I. Cost-effectiveness of hormone replacement therapy in the menopause. Obstetrical and Gynecological Survey 1983; 38: 445-55.

Weinstein MC, Tosteson AN. Cost-effectiveness of hormone replacement. Annals New York Academy of Sciences 1990; 592: 162-72.

Wiklund I, Karlberg J, Mattsson L-Å. Quality of life of postmenopausal women on a regimen of transdermal estradiol therapy: A double-blind placebo-controlled study. American Journal of Obstetrics and Gynecology 1993; 168: 824-30. 
Table 1. Mean values of the explanatory variables included in the logistic regressions ${ }^{\mathrm{a}}$.

\begin{tabular}{lccccccc}
\hline \hline & & & & & \multicolumn{3}{c}{ Household $^{2}$} \\
Variable & Bid & $\Delta \mathrm{TTO}^{\mathrm{b}}$ & $\Delta \mathrm{RS}^{\mathrm{b}}$ & Age & Income $^{\mathrm{c}}$ & size & Education $^{\mathrm{d}}$ \\
\hline TOTAL & 2,640 & 0.29 & 0.37 & 52.2 & 27,840 & 2.15 & 0.55 \\
Stand. Dev. & $(2,936)$ & $(0.28)$ & $(0.26)$ & $(3.87)$ & $(12,092)$ & $(0.98)$ & $(0.5)$ \\
\hline \hline
\end{tabular}

Notes:

${ }^{\text {a }}$ To be noted in interpreting the results of the present study is that the patient sample in the study may not be representative of the overall patient population receiving HRT in Sweden. Care should thus be taken in extrapolating the results to other populations and settings. To compare the patient population with women from the Swedish population, the mean values of the socio-economic variables household income, household size and education level were compared with the mean values for the Swedish population. The mean household size in the Swedish population is 2.1 and the monthly mean pre-tax household-income is SEK 18,500 (Statistisk årsbok 1995). The mean education level ${ }^{13}$ for women, $45-54$ years of age, is 0.7 (Statistisk årsbok 1995). Thus, the mean education level in the patient sample is lower compared to the mean education level for women in the Swedish population. However, the mean household income in the patient sample is above the mean household income in the Swedish population. Only the household size is similar in the patient sample and in the Swedish population.

${ }^{\mathrm{b}}$ The difference in the quality of life score with and without HRT.

${ }^{\mathrm{c}}$ Per month pre-tax household income.

${ }^{\mathrm{d}}$ Coded 0 for primary education and 1 for secondary and university or higher education.

\footnotetext{
${ }^{13}$ Coded 0 for primary education and 1 for secondary and university or higher education. 1 January, 1995.
} 
Table 2. Coefficients of the logistic regressions for the full sample (t-ratios are shown within parentheses).

\begin{tabular}{lcc}
\hline \hline Variable & Equation 1 & Equation 2 \\
\hline Intercept & 2.6524 & 1.7952 \\
Bid & $(0.72)$ & $(0.53)$ \\
& $-0.0004 * * *$ & $-0.0004 * * *$ \\
$\Delta$ TTO & $(-3.49)$ & $(-3.67)$ \\
& 1.2528 & $/$ \\
$\Delta$ RS & $(1.44)$ & $/$ \\
& $/$ & 1.2301 \\
Age & $/$ & $(1.31)$ \\
Income & -0.0443 & -0.0291 \\
& $(-0.67)$ & $(-0.48)$ \\
Education & $9.78 \times 10^{-6}$ & $1.00 \times 10^{-5}$ \\
Correctly predicted & $(0.44)$ & $(0.45)$ \\
Household size & 0.6267 & 0.8122 \\
& $(1.25)$ & $(1.61)$ \\
\hline W & -0.0734 & -0.1097 \\
\hline \hline Goodness of fit: & $(-0.27)$ & $(-0.41)$ \\
\hline & 104 & 104 \\
\hline
\end{tabular}

Notes: $*, * *, * * *$ Significant at $10 \%, 5 \%$ and $1 \%$ levels (two-sided t-test). 
Figure 1. The relationship between the bid level and the proportion of patients willing to pay the bid. $\mathrm{N}=104$.

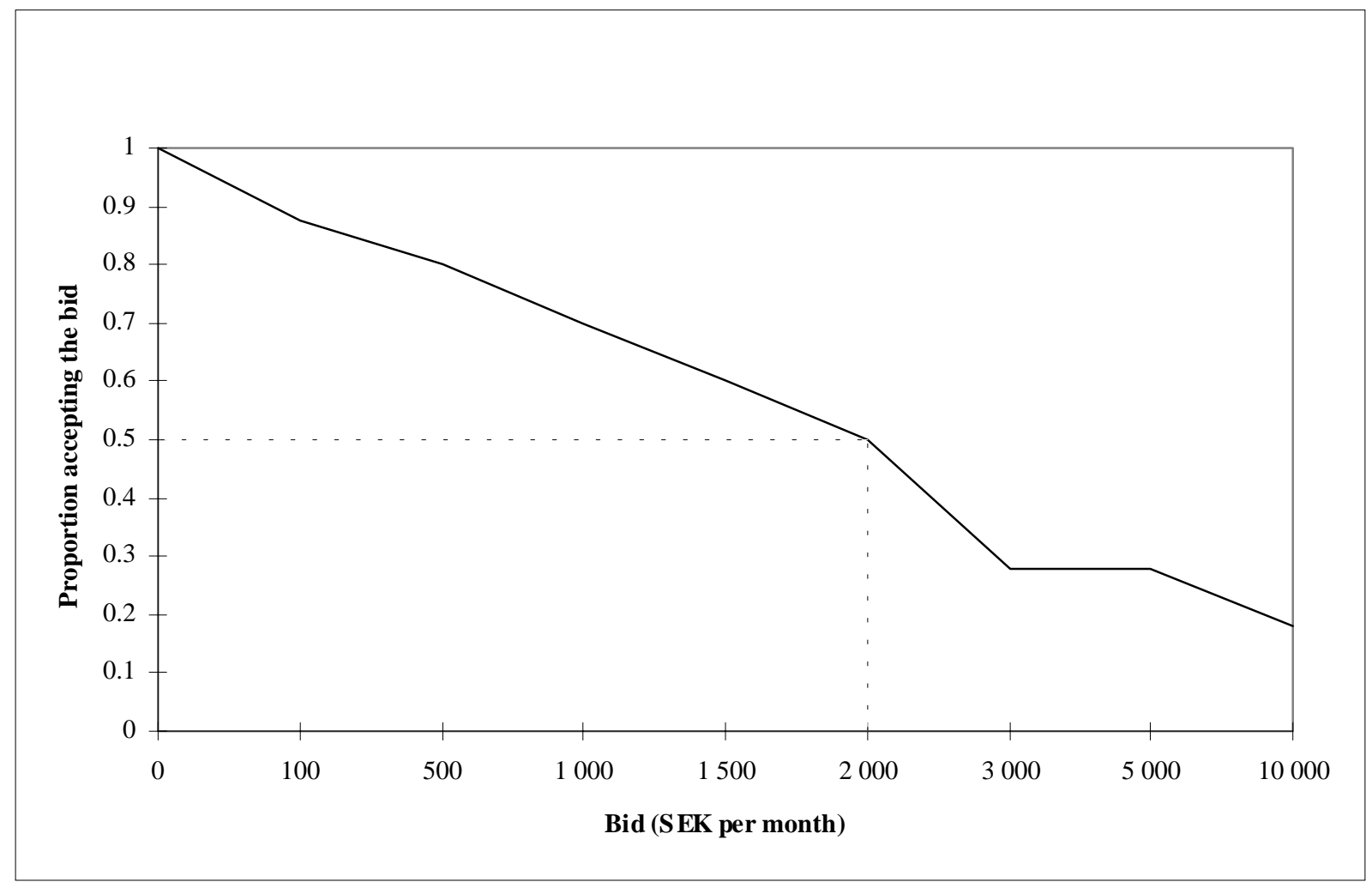




\section{$\underline{\text { Appendix } 1}$}

Necessary conditions for optimality include:

$\partial H(t) / \partial c(t)=u_{c}[c(t), h(t) ; T ; t] \alpha(t) \mu(t)-\lambda^{k}(t)=0$

$\partial H(t) / \partial x(t)=\lambda^{h}(t) f_{x}[x(t), t ; \beta(t)]-\lambda^{k}(t)=0$

$\partial H(t) / \partial k(t)=r(t) \lambda^{k}(t)=-\dot{\lambda}^{k}(t)$

$\partial H(t) / \partial h(t)=u_{h}[c(t), h(t) ; T ; t] \alpha(t) \mu(t)+\lambda^{\mu}(t) \delta_{h}[h(t), t]-\lambda^{h}(t) \gamma=-\dot{\lambda}^{h}(t)$

$\partial H(t) / \partial \Delta(t)=-u[c(t), h(t) ; T ; t] \alpha(t) \mu(t)=-\dot{\lambda}^{\mu}(t)$

$\lim _{t \rightarrow \infty} \lambda^{k}(t) k(t)=0$

$\lim _{t \rightarrow \infty} \lambda^{h}(t) h(t)=0$

$\lim _{t \rightarrow \infty} \lambda^{\mu}(t) \Delta(t)=0$

and equations (4)-(6). The transversality conditions (A.6)-(A.8), which here are expressed in terms of $\lambda^{i}(t)=\lambda^{i}(t ; T)\left[\alpha\left(T_{0}\right) \mu\left(T_{0}\right)\right]$ for $i=k, h, \mu$, require that certain growth conditions are satisfied. See Theorems 3.16 and 3.17 in Seierstad and Sydsaeter (1987). 


\section{Appendix 2}

The formulation of the willingness to pay question:

This question focuses on how much you value the continuation of your hormone replacement therapy. Presume that you have to pay the majority of the treatment costs for drugs and physician visits by yourself. Would you choose to continue your current treatment for menopausal symptoms if you had to pay SEK 1,000 each month ${ }^{14}$ as patient charges for the treatment? Be aware that the money is taken from your own disposable income and hence decreases your private consumption.

Alternatives:

Yes

No

Statements of your motives:

Follow-up question:

Are you sure or uncertain that you want to pay SEK 1,000 for continuing the hormone replacement therapy?

Certain

Uncertain

\footnotetext{
${ }^{14}$ The bid varies from SEK 100 to SEK 10,000 in eight subsamples.
} 